\title{
Humid Medieval Warm Period recorded by magnetic characteristics of sediments from Gonghai Lake, Shanxi, North China
}

\author{
LIU JianBao ${ }^{1}, \mathrm{CHEN} \mathrm{FaHu}^{1 *}, \mathrm{CHEN} \mathrm{JianHui}^{1}, \mathrm{XIA}^{2}$ DunSheng ${ }^{1}, \mathrm{XU} \mathrm{QingHai}^{2}$, \\ WANG ZongLi ${ }^{1} \&$ LI YueCong ${ }^{2}$ \\ ${ }^{1}$ Key Laboratory of Western China's Environmental System (Ministry of Education), Lanzhou University, Lanzhou 730000, China; \\ ${ }^{2}$ College of Resources and Environment, Hebei Normal University, Shijiazhuang 050016, China
}

Received February 15, 2011; accepted May 16, 2011

\begin{abstract}
Variations in monsoon strength, moisture or precipitation in eastern China during the MWP reflected by different climatic records have shown apparent discrepancies. Here, detailed environmental magnetic investigations and mineralogical analyses were conducted on lacustrine sediments of Core GH09B1 (2.8 m long) from Gonghai Lake, Shanxi, North China, concerning the monsoon history during the MWP. The results demonstrate that the main magnetic mineral is magnetite. The sediments with relatively high magnetic mineral concentrations were characterized by relatively fine magnetic grain sizes, which were formed in a period of relatively strong pedogenesis and high precipitation. In contrast, the sediments with low magnetic mineral concentrations reflected an opposite process. The variations of magnetic parameters in Gonghai Lake sediments were mainly controlled by the degree of pedogenesis in the lake drainage basin, which further indicated the strength of the Asian summer monsoon. The variations in the $\chi$ and $S_{-300}$ parameters of the core clearly reveal the Asian summer monsoon history over the last 1200 years in the study area, suggesting generally abundant precipitation and a strong summer monsoon during the Medieval Warm Period (MWP, AD 910-1220), which is supported by pollen evidence. Furthermore, this 3-6-year resolution environmental magnetic record indicates a dry event around AD 980-1050, interrupting the generally humid MWP. The summer monsoon evolution over the last millennium recorded by magnetic parameters in sediments from Gonghai Lake correlates well with historical documentation (North China) and speleothem oxygen isotopes (Wanxiang Cave), as well as precipitation modeling results (extratropical East Asia), which all indicate a generally humid MWP within which centennial-scale moisture variability existed. It is thus demonstrated that environmental magnetic parameters could be used as an effective proxy for monsoon climate variations in high-resolution lacustrine sediments.
\end{abstract}

Gonghai Lake, lacustrine sediments, magnetic parameter, Medieval Warm Period, humid climate

Citation: $\quad$ Liu J B, Chen F H, Chen J H, et al. Humid Medieval Warm Period recorded by magnetic characteristics of sediments from Gonghai Lake, Shanxi, North China. Chinese Sci Bull, 2011, 56: 2464-2474, doi: 10.1007/s11434-011-4592-y

Magnetic measurements provide a rapid, cheap and nondestructive way to characterize high-resolution mineralogical variations, which are widely used in sequence correlation, paleoclimate and provenance studies of marine [1,2], lacustrine [3] and aeolian sediments [4,5]. They have become one of the most important proxies in paleoenvironment and paleoclimate reconstructions [6,7]. However, due to the low magnetic mineral concentrations in lacustrine sediments and the authigenesis/diagenesis and biogenesis in

\footnotetext{
*Corresponding author (email: fhchen@lzu.edu.cn)
}

situ after deposition which may result in the formation of new magnetic minerals [8,9], the magnetic parameters that can be used to reveal sensitive short-scale (decadal to centennial scale) climatic and environmental events remain undetermined and are a problem requiring urgent attention.

Global climate evolution over the last millennium is known to have varied dramatically. It can be roughly divided into three major episodes: the Medieval Warm Period (MWP), the Little Ice Age (LIA), and post-industrial warming [10-14]. The MWP in the Northern Hemisphere is about $0.5-0.8^{\circ} \mathrm{C}$ warmer on average than the LIA $[13,14]$. 
In eastern China, the winter half-year temperatures of two centennial warm periods within the MWP are even higher than those observed in the 20th century [15]. In recent years, considerable research interest in MWP climate variability has arisen [13,16-18], because the centennial-scale warm intervals of the MWP are closest to those of the modern age, and can thus provide a complete paleoclimatic analog for long-term climate prediction. During this interval, many regions of the globe experienced hydroclimate anomalies $[19,20]$. However, compared with the relatively uniformlychanged temperature, moisture and precipitation showed significant regional differences during the MWP. For example, the central and western part of America experienced a mega-drought during the MWP [21], while periods of high precipitation dominated the eastern part of the United Kingdom during the same time [22,23]; in other regions, no obvious anomaly was seen [24]. In China, regional differences in hydroclimatic characteristics during the MWP also clearly existed. In arid northwestern China, the proxy records derived from lacustrine sediments [25,26], aeolian deposits [27] and tree rings [28] all show a dry MWP and a wet LIA in general [29]. The Asian summer monsoon is an important component of global climate system and its variability is always of great interest in paleoclimatological studies at a wide range of time scales [30,31]. As far as the monsoon climate over last millennium is concerned, the Asian summer monsoon has been found to be relatively weak, and the climate was relatively dry in eastern China during the LIA [32-34]. However, there is no consensus achieved about monsoon climate conditions during the MWP. For example, a pollen record from northeastern China suggests that the Asian summer monsoon was strong during the MWP [33], which is supported by a recently published high-resolution speleothem oxygen isotope record from the summer monsoon margin [35]. Conversely, speleothem oxygen isotope records from some other regions show that the Asian summer monsoon was not strong in MWP [36,37]. Furthermore, a stacked speleothem oxygen isotope record has demonstrated that the summer monsoon was not significantly abnormal during the MWP, and was even slightly weaker from the 11 th to early 13 th century [38]. Two historical document-based humidity reconstructions indicate a relatively wet period in North China during the MWP [39,40], but it has been suggested by another document-based record that there was a dry MWP over the whole of eastern China [41]. Therefore, variations in monsoon strength, moisture or precipitation in eastern China during the MWP reflected by different climatic records have shown apparent discrepancies. This could due to the fact that different proxies may have different paleoclimatic implications, or that the strength of the Asian monsoon may have a different effect on precipitation in different regions of eastern China. According to conventional concepts, the abnormal northward extension of the southerlies into North China and associated increased precipitation in North China could be regarded as signs of an intensified Asian summer monsoon $[42,43]$. It is therefore particularly important that high-resolution climate records over the last millennium are obtained in this critical region. Here, we choose a paleolimnological site, Gonghai Lake in northern Shanxi, which is located at the northern boundary of the modern Asian summer monsoon, to carry out a high-resolution and multi-parameter investigation on environmental magnetism of a sediment core. On the basis of environmental magnetism results, the aims of this study are to explore the magnetic characteristics of Gonghai Lake sediments in combination with other proxies and to reconstruct the regional climate and environment change over the last millennium, with particular attention to the evolution of the Asian summer monsoon and associated precipitation during the MWP.

\section{Study site and sampling}

Gonghai Lake $\left(38^{\circ} 54^{\prime} \mathrm{N}, 112^{\circ} 14^{\prime} \mathrm{E}\right.$, elevation $1860 \mathrm{~m}$ a.s.1.) is located in Dongzhuang, Ningwu County, Shanxi Province, in the northern part of the Lüliang Mountains. It is a lake formed on a planation surface of the watershed between the Sanggan and Fenhe rivers. Eleven small lakes including Gonghai Lake are distributed on the planation surface (the average altitude is $1800 \mathrm{~m}$ a.s.1.), which make up a rare group of high-mountain lakes in North China [44]. Among these lakes, Gonghai Lake is at the highest altitude and has a maximum water depth of around $10 \mathrm{~m}$ and a surface of $0.36 \mathrm{~km}^{2}$. Gonghai Lake is hydrologically closed, and has a flat lakebed; its main water source is precipitation (Figure 1). The Ningwu area is close to the sandy deserts and sandy lands of central China to the north and west (e.g. Maowusu Sandy Land, Kubuqi Desert, Badain Jaran Desert and Tengger Desert), falling into the typical fringe of the modern Asian summer monsoon (Figure 1). The mean annual precipitation in Ningwu (1500 m a.s.l.) is about $468 \mathrm{~mm}$, with about $65 \%$ of the annual precipitation occurring in the summer (from June to August). Regional vegetation in the mountains (including the drainage basin of Gonghai Lake) is dominated by mixed coniferous and broad-leaved forests, whereas in the mountains with an elevation lower than the planation surface, coniferous forests are widely distributed. Zonal soil types consist mainly of mountain-meadow soil, brown soil, cinnamon soil, chestnut soil and meadow soil, of which the cinnamon soil is the major zonal soil type. The exposed bedrock of the zonal ground surfaces was mainly formed during the Archeozoic to Cenozoic, and is comprised mainly of weakly-magnetic rock, such as dolomite, limestone, sandstone, sandy shale, and glutenite [46]. This provides good conditions for conducting environmental magnetism research using lacustrine sediments. In January 2009, we drilled at Gonghai Lake using a Piston Corer on a UWITEC platform (UWITEC, Mondsee, Austria). A long core of $7.68 \mathrm{~m}, \mathrm{GH} 09 \mathrm{~B}$, was retrieved at the center of the 


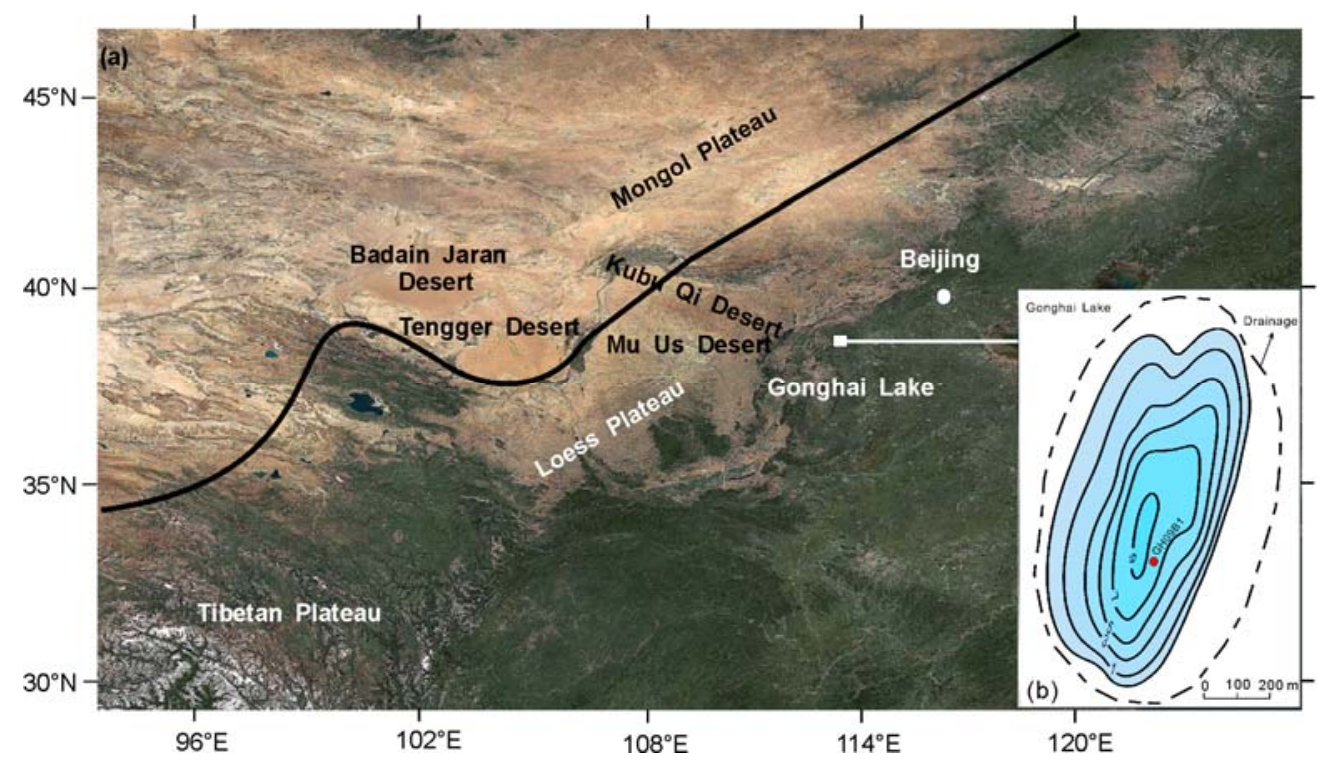

Figure 1 (a) Remote sensing image showing the location of Gonghai Lake and surrounding geographic features. Black solid line indicates the modern Asian summer monsoon limit [45]. (b) Bathymetry of Gonghai Lake. The red dot indicates the location of core GH09B1.

lake in a water depth of $8.96 \mathrm{~m}$ (Figure 1). Also, 15 bedrock samples and 3 soil samples were taken around the lake drainage basin on the ground surface. The samples were frozen on-site and taken back to the laboratory where they were stored in a freezer below $4^{\circ} \mathrm{C}$. The 2.8 -m-long first tube of core GH09B (named GH09B1) provides material for this study. There is no significant change in the lithology of core GH09B1, which mainly consists of the silty clay. The sediments are coarser at depths of around 1.0 and $2.0 \mathrm{~m}$, and from depths of 2.5 to $2.8 \mathrm{~m}$. In the laboratory, the core GH09B1 was sliced at $1 \mathrm{~cm}$ intervals for magnetic analysis, and the samples were freeze-dried and then ground.

\section{Laboratory methods}

All environmental magnetic parameters were measured and calculated following the procedure of Dearing et al. [47]. Low-field $(470 \mathrm{~Hz})$ and high-field $(4700 \mathrm{~Hz})$ frequency magnetic susceptibility $\left(\chi_{\mathrm{lf}}\right.$ and $\left.\chi_{\mathrm{hf}}\right)$ were measured using a Bartington MS2 magnetometer (Bartington Instruments Ltd, Witney, UK). Anhysteretic remanent magnetization (ARM) was performed using a DTECH AF demagnetizer (2G Enterprises, California, USA) with a peak AF field of $50 \mathrm{mT}$ and DC bias field of $0.05 \mathrm{mT}$. Stepwise demagnetization of saturation isothermal remanent magnetization (SIRM) at 1 $\mathrm{T}$ was carried out using three reverse fields $(-20,-100$, and $-300 \mathrm{mT}$ ). IRMs were performed using an MMPM 5 pulse magnetizer (2G Enterprises, California, USA). All remanence measurements were made using a Minispin magnetometer (Advanced Geoscience Instruments Company, Brno, Czech). Magnetic parameters are all expressed on both mass-specific and quotient bases to give quantitative and qualitative information of $\chi_{\text {lf }}\left(\times 10^{-8} \mathrm{~m}^{3} / \mathrm{kg}\right)$, SIRM $(\mathrm{SIRM}=$
$\left.\mathrm{IRM}_{1000 \mathrm{mT}}\right)\left(\times 10^{-5} \mathrm{Am}^{2} / \mathrm{kg}\right), \chi_{\mathrm{ARM}}\left(\times 10^{-8} \mathrm{~m}^{3} / \mathrm{kg}\right), \chi_{\mathrm{fd}} \%\left(\chi_{\mathrm{fd}} \%\right.$ $\left.=\left[\chi_{\mathrm{lf}-} \chi_{\mathrm{hf}}\right] / \chi_{\mathrm{lf}} \times 100\right), \chi_{\mathrm{ARM}} / \chi, \chi_{\mathrm{ARM}} / \mathrm{SIRM}\left(\times 10^{-3} \mathrm{~m} / \mathrm{A}\right), \operatorname{SIRM} / \chi$ $(\times \mathrm{kA} / \mathrm{m})$ and S-ratio (IRM-300/SIRM). A subset of representative samples (50 samples) was selected for further magnetic measurements: magnetic hysteresis loops and $\mathrm{Cu}-$ rie temperatures $\left(T_{\mathrm{c}}\right)$ were determined using a variable field translation balance (Petersen Instruments, Muenchen, Germany). Five representative samples were selected for X-ray diffraction analysis using D/max-3BX equipment (Rigaku, Tokyo, Japan); scans were run from $4^{\circ}$ to $80^{\circ}$ of $2 \theta$ at a step width of $0.02^{\circ}$. Also, eight representative samples were selected for pollen analysis following the procedure of Moore et al. [48]. The pollen analysis was conducted in the laboratory of Hebei Normal University. All other experiments were conducted in the Key Laboratory of Western China's Environmental Systems, Lanzhou University.

\section{Results}

\subsection{Chronology}

In core $\mathrm{GH} 09 \mathrm{~B} 1$, all $\mathrm{AMS}{ }^{14} \mathrm{C}$ dates were generated from samples of terrestrial plant macrofossils, which can avoid the carbon reservoir effects that commonly occur in lacustrine sediments. The AMS ${ }^{14} \mathrm{C}$ samples were all first prepared with the standard pretreatment (alkali-acid-alkali) and then measured at the AMS Dating Laboratory of the Institute of Earth Environment, Chinese Academy of Sciences, Xi'an, China. All dates were calibrated to calendar years using OXCAL4.1 software [49] using the IntCal04 calibration data set [50]; ages determined included $415 \pm 83 \mathrm{cal} \mathrm{a}$ $\mathrm{BP}$ at $0.63 \mathrm{~m}$ depth, $617 \pm 52 \mathrm{cal}$ a $\mathrm{BP}$ at $1.16 \mathrm{~m}$ depth, $884 \pm 80 \mathrm{cal}$ a BP at $1.99 \mathrm{~m}$ depth and $1011 \pm 43 \mathrm{cal}$ a BP at 
$2.45 \mathrm{~m}$ depth. These ages are precise enough to control the date range of the MWP. The dates of the other samples were obtained by interpolation, and the date at the bottom of core GH09B1 is AD 840. The time resolution between samples is about 4 to 8 years since AD 1300, and 3 to 6 years before AD 1300.

\subsection{Compositions and types of magnetic minerals}

Thermomagnetic curves for all samples from core GH09B1 are similar to each other (Figure 2(a),(b)). With increasing temperature, the magnetization first decreased slightly, then increased rapidly after $450^{\circ} \mathrm{C}$, and reached a peak at around $500^{\circ} \mathrm{C}$. This may reflect that paramagnetic minerals, such as iron silicate or clay minerals, were transformed into new magnetic minerals [51]. The cooling curves of the samples lie above the heating curves, which further supports that many new magnetic minerals are formed during the heating treatment. By further increasing the temperature, the mag- netization gradually reduces and approaches zero at $580^{\circ} \mathrm{C}$, the Curie point of magnetite. This behavior indicates that magnetite is the major magnetic mineral in the samples. The shape of the hysteresis loop was reversible within the magnetization of $300 \mathrm{mT}$ (Figure 2(e),(f)), indicating that the magnetite was also the main magnetic mineral contributor in the hysteresis loop. The magnetization is still increasing and not saturated even when the magnetic field reaches $1000 \mathrm{mT}$, further indicating that there is a large fraction of paramagnetic minerals existing in the GH09B1 core samples [52].

The main peaks from X-ray diffraction analysis are found to be very similar (Figure 3(a),(b)). This suggests that the mineral compositions of the GH09B1 core samples are the same. Samples consist mainly of quartz, albite, plagioclase, orthoclase, amphibole, illite, mica, magnetite, and carbonate (mainly calcite), as well as iron-rich chlorite clay minerals. This further supports the result, acquired by analysis of thermomagnetic curves and hysteresis loops, that the
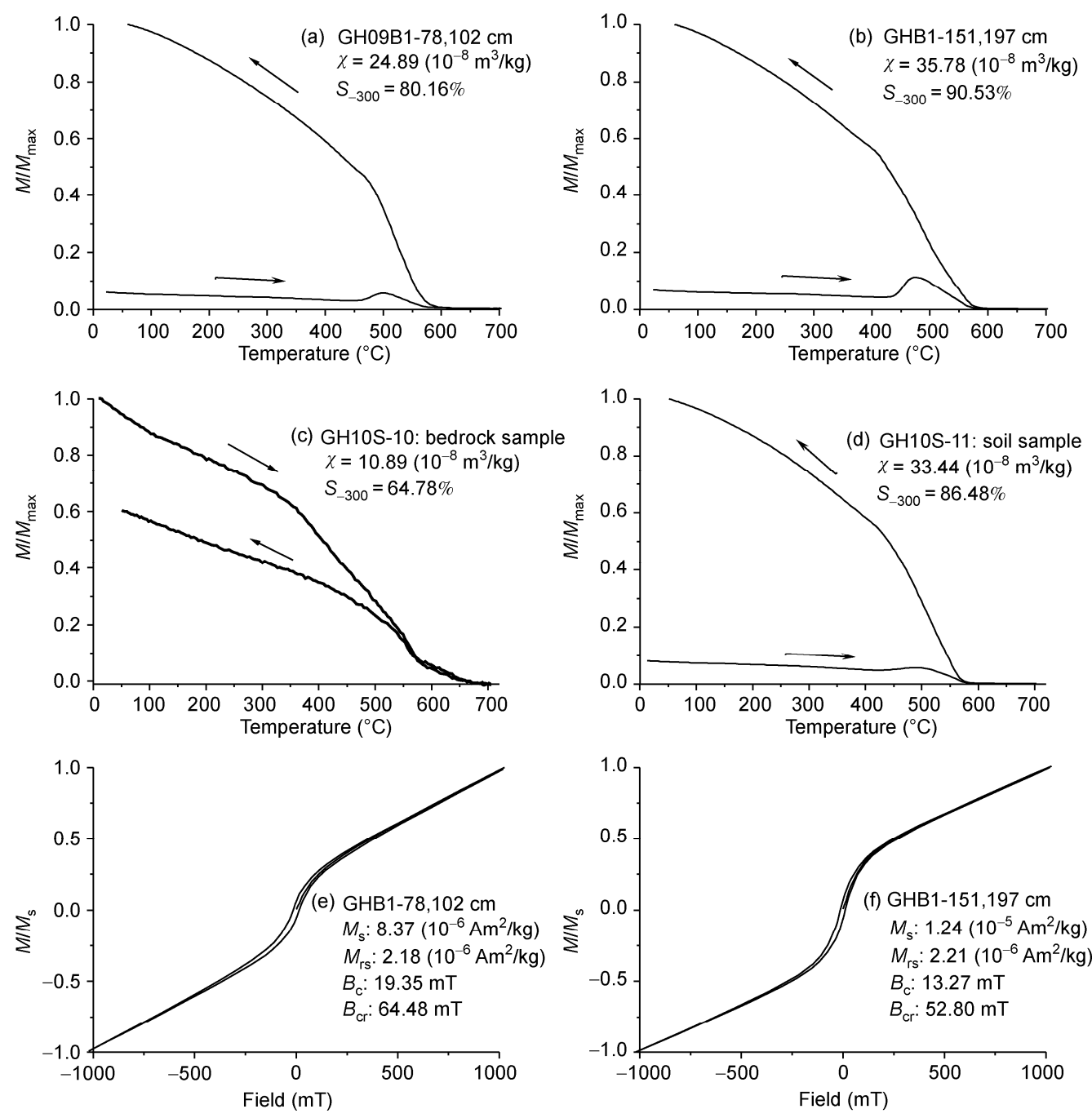

Figure 2 Thermomagnetic curves of GH09B1 core samples ((a), (b)), catchment bedrock samples (c) and catchment soil samples (d) in a 1.1 T field, and the magnetic hysteresis loops of GH09B1 core samples ((e), (f)). 

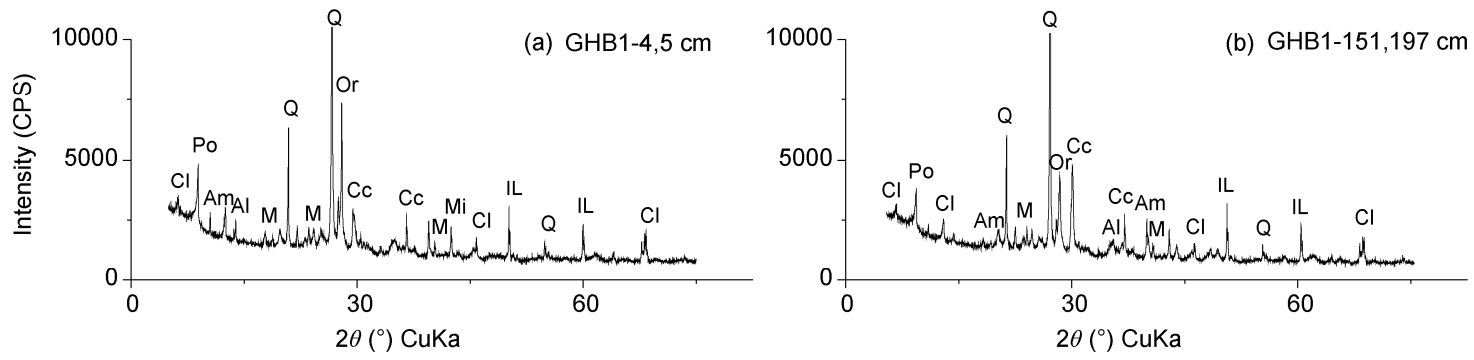

Figure 3 X-ray diffraction spectra of the typical GH09B1 core samples. CL, iron-rich chlorite; Po, plagioclase; Am, amphibole; Al, albite; M, magnetite; Q, Quartz; Or, orthoclase; Cc, calcite; Mi, mica; IL, illite.

magnetic assemblage in GH09B1 core samples is dominated by magnetite and the minerals are associated with quite a few paramagnetic minerals such as iron silicate or clay minerals. The ratio of SIRM to susceptibility is suited for assessing mineralogy. For example, the values of the ratio in pyrrhotite and greigite is around $100 \mathrm{kA} / \mathrm{m}$; hematite has a high ratio (higher than $200 \mathrm{kA} / \mathrm{m}$ ), but magnetite has low SIRM to susceptibility which is lower than $30 \mathrm{kA} / \mathrm{m}$ and usually around $10 \mathrm{kA} / \mathrm{m}[53,54]$. The average value of saturation isothermal remanent magnetization to susceptibility of all samples in core GH09B1 is $13.25 \mathrm{kA} / \mathrm{m}$ (Figure 6), which also supports that the dominant magnetic carrier in GH09B1 core samples is magnetite.

\subsection{Granularity of magnetic minerals}

The granularity of the magnetite in sediment could be identified by the Day plot between the magnetization intensity ratio $\left(M_{\mathrm{rs}} / M_{\mathrm{s}}\right)$ and coercivity ratio $\left(B_{\mathrm{cr}} / B_{\mathrm{c}}\right)$ [55-57]. The critical value of granularity follows that provided by Dunlop et al. [56,57]: Single domain (SD) magnetic grains are characterized by $M_{\mathrm{rs}} / M_{\mathrm{s}}>0.5$ and $B_{\mathrm{cr}} / B_{\mathrm{c}}<2.0$, multi-domain (MD) magnetic grains are characterized by $M_{\mathrm{rs}} / M_{\mathrm{s}}<0.02$ and $B_{\mathrm{cr}} / B_{\mathrm{c}}>5$, and pseudo-single domain (PSD) grains lie between MD and SD grains. Figure 4 shows that GH09B1 core samples are all in the PSD region, indicating that most of the magnetic grains in the lacustrine sediments of Gonghai are PSD. However, the mixtures of MD and SD magnetic grains in sediments might also scatter in the PSD region in the Day plot [58]. Dearing et al. [59] demonstrated that magnetic grain size in sediment can be effectively portrayed by combining $\chi_{\mathrm{FD}} \%$ and $\chi_{\mathrm{ARM}} / \mathrm{SIRM}$ data in a quantitative mixing model. All the GH09B1 core samples are almost found in the coarse stable single domain (SSD) region and only few samples in the MD+PSD region (Figure 5), further indicating that the most of the magnetic grains in lacustrine sediments from Gonghai Lake are coarse SSD. The surface samples that come from the top of the core contain MD+PSD magnetic grains, indicating that the MD+PSD magnetic grains in GH09B1 lake samples may have blown in from atmospheric pollutants, because MD+ PSD grains are the main grains of atmospheric pollutants found in North China [60]. Susceptibility of ARM $\left(\chi_{\text {ARM }}\right)$

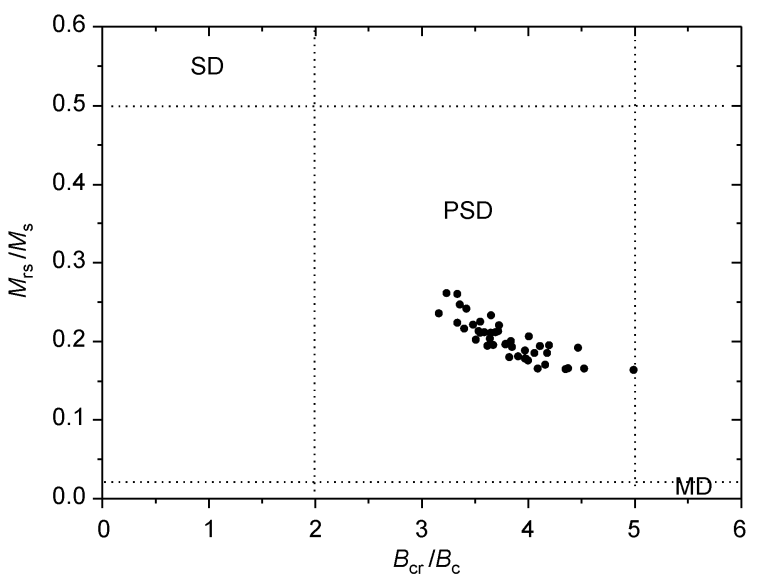

Figure 4 Day plot of the GH09B1 core samples.

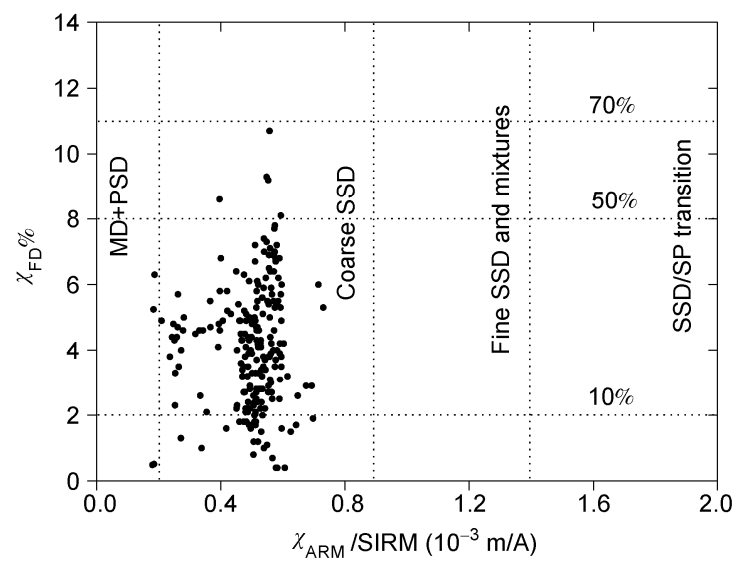

Figure 5 Dearing plot of GH09B1 core samples.

that reflects the concentration of SSD magnetic grains has a positive correlation with magnetic susceptibility [6], also supporting that the granularity of magnetic minerals in GH09B1 core samples is dominated by SSD grains, except for the recent 100 years at the top of core.

\subsection{Variations in magnetic parameters with depth}

Based on magnetic susceptibility $(\chi)$, core GH09B1 could be divided into four sections. In the first section (2.80-2.55 $\mathrm{m}$, AD 840-910), the magnetic susceptibilities are the low- 
est observed along the whole core. In the second section (2.55-1.50 m, AD 910-1220), the magnetic susceptibilities are high in general, and reached a peak for the core, indicating that the concentration of magnetite in the lacustrine sediments is high. However, during AD 980-1050, the magnetic susceptibility also shows relatively low values forming a trough throughout this section. In the third section (1.50-0.21 m, AD 1220-1850), the magnetic susceptibility decreases gradually and is relatively low compared with the core in general; the lowest values appear between the depths of 1.35 and $0.80 \mathrm{~m}$ (AD 1270-1450). In the fourth section (0.21-0 m, AD 185 to the present), the magnetic susceptibility increases rapidly with increasing magnetic concentration. However, the variation in this section is large, and the value is generally lower than the second section.

$S_{-300}$ is a proxy of the proportion of low-coercivity ferrimagnetic grains to high-coercivity antiferromagnetic grains [61]. Values above $80 \%$ reflect the dominance of magnetite (maghemite), whereas values below this percentage represent increasing contributions from antiferromagnetic minerals (hematite or goethite) [62]. The values of $S_{-300}$ in core GH09B1 are all above $80 \%$, which identifies magnetite as the dominant magnetic minerals (Figure 6). This result is in accordance with the analysis of thermomagnetic curves and hysteresis loops, i.e. that the magnetic assemblage in GH09B1 core samples is dominated by magnetite. The changes in $S_{-300}$ and magnetic susceptibility along the whole core show a consistent trend (Figure 6), which indicates that the magnetic susceptibility in GH09B1 core samples mainly reflect the content of magnetite. The trend of change in SIRM along the whole core is basically consistent with magnetic susceptibility and $S_{-300}$ (Figure 6), which also in- dicates that the superparamagnetic (SP) magnetic grains make only a small contribution to the intensity of magnetism [6]. In addition, most of the magnetic grains in samples are SSD. Therefore, the magnetic susceptibility and $S_{-300}$ mainly reflect the concentration of magnetite in the samples.

The variation in the trend of $\chi_{\mathrm{ARM}} / \chi$ is basically consistent with that of $\chi_{\mathrm{ARM}} / \mathrm{SIRM}$. They show troughs at the bottom of the core (below a depth of $2.55 \mathrm{~m}$ ), at a depth of $\sim 2.2 \mathrm{~m}$ (during the middle of the MWP, AD 980-1050) and at the top of the core (in the last 50 years) (Figure 6). The ratios of $\chi_{\mathrm{ARM}} / \chi$ and $\chi_{\mathrm{ARM}} / \mathrm{SIRM}$ can reflect grain sizes of ferrimagnetic minerals, especially fine-grained magnetite. For example, when magnetic grain sizes are smaller (or larger) in samples, values of $\chi_{\text {ARM }} / \chi$ and $\chi_{\text {ARM }} / S I R M$ are higher (or lower) $[63,64]$. Similar variations in the trends of $\chi_{\mathrm{ARM}} / \chi$ and $\chi_{\mathrm{ARM}} / \mathrm{SIRM}$ suggests that magnetic grains formed in the MWP are fine in general, but become coarse during AD 980-1050. The values of SIRM reflect grain sizes of magnetic minerals becoming lower during AD 980-1050. This suggests that the low values of $\chi$ and $S_{-300}$ during AD 980-1050 result from the change in magnetic grain sizes. Since AD 1850 , the ratios of $\chi_{\mathrm{ARM}} / \chi$ and $\chi_{\text {ARM }} /$ SIRM have evidently decreased, indicating that the magnetic grain sizes become larger. However, during this period, values of $\chi$ and $S_{-300}$ are still consistent with the conditions of a high-value period (Figure 6), indicating that the intensity of magnetism in the samples is strong. Obviously, this is different from the low values of $\chi_{\mathrm{ARM}} / \chi$ and $\chi_{\mathrm{ARM}} / \mathrm{SIRM}$ that result in the low values of $\chi$ and $S_{-300}$ during the middle of the MWP (AD 980-1050). This difference may indicate that the coarse magnetic minerals in the lake

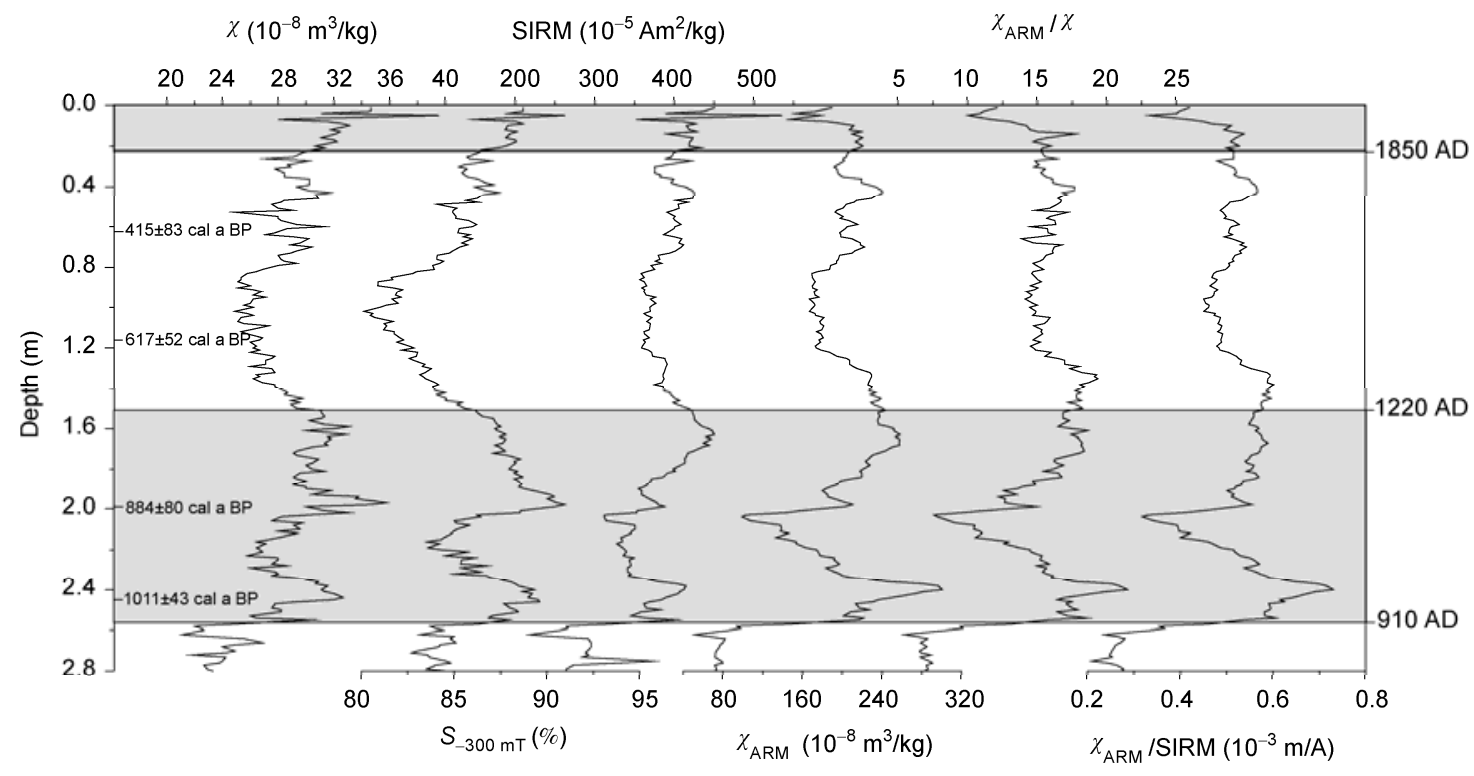

Figure 6 Main magnetic parameters of GH09B1 core samples as a function of depth. The radiocarbon dates are marked beside the depth. The shaded areas represent the extrapolated data ranges of periods with high-value $\chi$ and $S_{-300}$. 
were sourced by air pollution from the city of Ningwu near Gonghai Lake since AD 1850.

\section{Discussion}

\subsection{Origin of magnetic minerals and their paleoclimatic significance}

Magnetic minerals in lacustrine sediments can originate from detrital or authigenic sources [6]. In Gonghai Lake, magnetic assemblage in the sediments is dominated by SSD or PSD magnetite, either of which could come from a detrital or authigenic origin. The ratios of $\chi_{\mathrm{ARM}} / \chi, \chi_{\mathrm{ARM}} / \chi_{\mathrm{FD}}$ and ARM/SIRM reflect the grain sizes of the magnetic minerals. The mean value of $\chi_{\mathrm{ARM}} / \chi$ is 6.69 (maximum value does not surpass 25 , Figure 6), the average value of $\chi_{\mathrm{ARM}} \chi_{\mathrm{FD}}$ is 65.14 , and the range of ARM/SIRM is between 0.016 and 0.058 . The values of these ratios in magnetic parameters are all quite low, belonging to the range of values of detrital origin $[65,66]$. The magnetite in Gonghai Lake sediments primarily represents detrital input rather than authigenic/biogenesis produced magnetite in situ after deposition. The detrital input of magnetic minerals may originate either from atmospheric dust or as lake drainage from ground surface runoff.

Except in the section above $0.14 \mathrm{~m}$ in the core, the changes in $\chi$ and $S_{-300}$ have a positive correlation with those of $\chi_{\mathrm{ARM}} / \chi$ and $\chi_{\mathrm{ARM}} / \mathrm{SIRM}$, indicating that the sediments with higher magnetic mineral concentration are characterized by smaller magnetic grain sizes (i.e. the higher the $\chi$, the finer the magnetic grain size, Figure 6). This is usually relevant with the pedogenic processes. The detailed mineral magnetic measurements on the bedrock and the soil from the drainage area of Gonghai Lake were also conducted. In the bedrock samples, the average value of $\chi$ is only 9.12 $\left(\times 10^{-8} \mathrm{~m}^{3} / \mathrm{kg}\right)$ and the highest value is $13.2\left(\times 10^{-8} \mathrm{~m}^{3} / \mathrm{kg}\right)$. The values of $S_{-300}$ are also very low (between $58.5 \%$ and $73.9 \%$ ). The features of the thermomagnetic curves (Figure 2(c)) are evidently different from those in the core samples (Figure 2(a),(b)), indicating that the dominant magnetic mineral is hematite. The average value of $\chi$ of the soil samples is $28.9\left(\times 10^{-8} \mathrm{~m}^{3} / \mathrm{kg}\right)$ and the lowest value is higher than $22\left(\times 10^{-8} \mathrm{~m}^{3} / \mathrm{kg}\right)$. The average value of $S_{-300}$ is $85.2 \%$ and all the values are higher than $80 \%$. The features of the thermomagnetic curves (Figure 2(d)) are similar to those in the core samples (Figure 2(a), (b)), indicating that the dominant magnetic mineral is in this case is magnetite. The dominant magnetic carriers in the atmospheric dust are ferromagnetic minerals with the main magnetic grain sizes of a PSD [60,67]. Therefore, the magnetite in GH09B1 core samples was all formed in the process of pedogenesis around the lake drainage area from the ground surface, rather than in the process of the atmospheric dust accumulation. The magnetic characteristics of core GH09B1 and the soil in the lake drainage area are the same (e.g. the characteristics of the thermomagnetic curves), which further sug- gests that the effect of diagenesis on magnetic minerals in lacustrine sediments is limited. As a result, the concentration of magnetite in Gonghai Lake can reflect the degree of pedogenesis in the lake catchment.

In the Chinese Loess Plateau, abundant fine magnetic grains have been formed by pedogenic processes [68]. The changes in magnetic susceptibility in modern surface soils have a positive correlation with changes in precipitation [69]. The $\chi$ and other environmental magnetic parameters were successfully used as indicators of the strength of Asian summer monsoon [5], and successfully enabled the reconstruction of the evolutionary history of the Quaternary monsoon [30] and rapid changes in monsoon climate [70] during the last glaciation in East Asia. Gonghai Lake is located on the margin of the Chinese Loess Plateau. The lake drainage area is covered by variable thicknesses of loess. The magnetic minerals of the core originate from the lake drainage on the ground surface by soil erosion. The changes in magnetic parameters could record the degree of pedogenesis in soil, and thereby constrain the evolutionary history of the monsoon. When the degree of pedogenesis is higher, the magnetic grain sizes produced in the process of pedogenesis would be finer and the concentration of magnetic minerals in soil will be also higher. Greater concentrations of magnetic minerals flowing into Gonghai Lake via surface runoff lead to high values of $\chi$ and $S_{-300}$.

To verify this model, some samples from the core were selected for a pollen analysis (Figure 7(g)). The modern vegetation in the Gonghai Lake catchment area includes grasslands and shrubs. A mixed coniferous and broadleaved forest is located below the planation surface on which Gonghai Lake is located. The content of the tree pollen at this area could reflect the amount of precipitation in this region. In the semi-drought/semi-humid areas of China, when the content of the tree pollen is lower than $50 \%$, the Artemisia to Chenopodiaceae (A/C) ratio in the pollen spectrum is also a good indicator of the effective moisture [71-74]. In the pollen spectrum of core GH09B1, the highest content of the tree pollen, up to $47.2 \%$, is at a depth of $1.97 \mathrm{~m}$ with the concentration of broad-leaved tree pollen almost as high as the concentration of coniferous tree pollen, indicating that the mixed broad-leaved and coniferous forest developed during the period. The lowest concentration of tree pollens is at a depth of $1.05 \mathrm{~m}$ where its content is lower than 7\%; even lower than the concentration of tree pollen in the lake-surface sample. The high content of tree pollen of the samples correlates very well with the high values of $\chi$ and $S_{-300}$ in the samples. The changes in the $\mathrm{A} / \mathrm{C}$ ratio in the pollen spectrum are consistent with those of the content of tree pollen (Figure $7(\mathrm{~g})$ ), which suggests that during the high values of $\chi$ and $S_{-300}$ period, the climate is dominated by high precipitation and a strong Asian monsoon. As a result, in core GH09B1, $\chi$ and $S_{-300}$ can be used as sensitive indicators of the Asian summer monsoon, where higher values of $\chi$ and $S_{-300}$ indicate stronger Asian summer monsoons. 


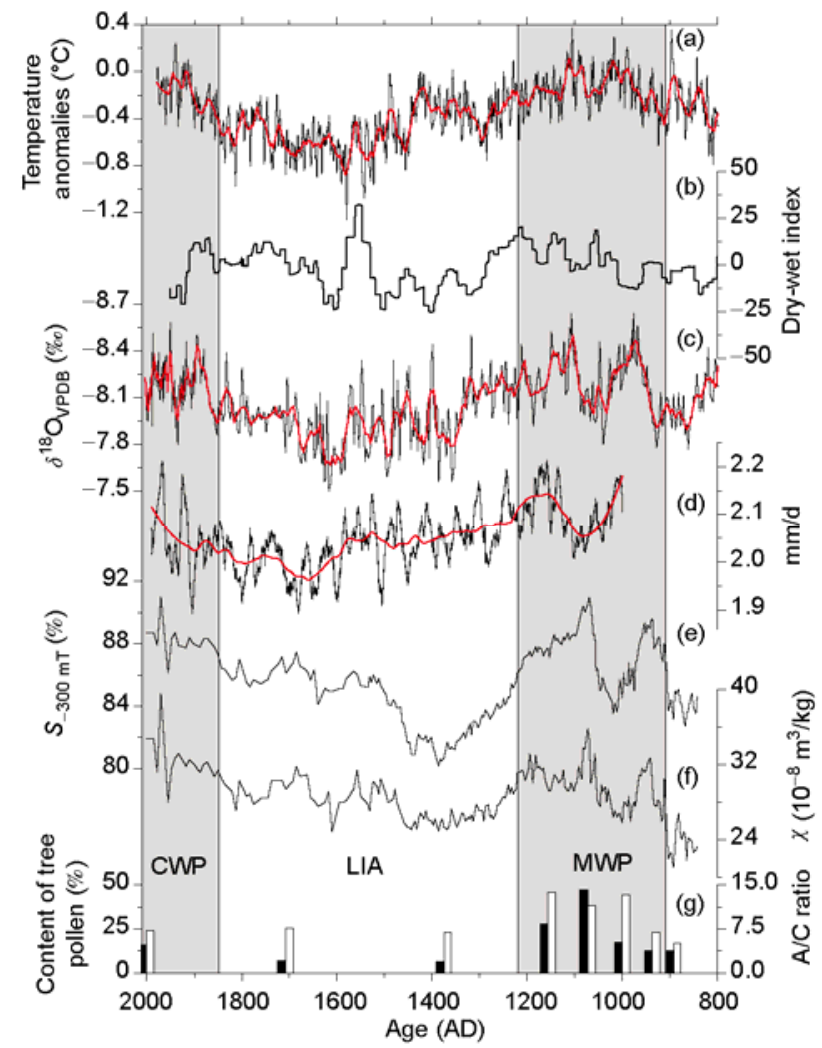

Figure 7 Variations in $\chi$ (f) and $S_{-300}$ (e) with time over the last millennium, and their comparisons with modeled Asian monsoon strength in North China (d) [43], speleothem oxygen isotope time series from Wangxiang Cave (c) [35], dry-Wet index record inferred from historical documentation in North China (b) [40] and temperature anomalies in the Northern Hemisphere (a) [14]. The solid histogram and hollow histogram respectively represent the content of tree pollen and A/C (g). The shaded areas represent the MWP and the Current Warm Periods.

\subsection{Strong summer monsoons during the MWP and regional comparisons}

The base of core GH09B1 is dated at AD 840. Above this, the $\chi$ and $S_{-300}$ can be divided into two high-value periods and two low-value periods (Figure 7(f),(e)). The two high-value periods lasted from AD 910 to 1220 and from AD 1850 to the present, which correspond to the MWP and the Current Warm Period (i.e. the 20th-century warm period), respectively [14] (Figure 7(a)). The two low-value periods lasted from AD 840 to 910 and from AD 1220 to 1850 , with the latter corresponding to the LIA [14] (Figure 7(a)). Evidently, the most distinct climate fluctuations during the last millennium in Northern Hemisphere have been well documented in sediments from Gonghai Lake. Concerning the changes in $\chi$ and $S_{-300}$, the generally high values from AD 910 to 1220 suggest that the degree of pedogenesis was remarkable and that precipitation was high in that time, indicating a strong Asian summer monsoon during the MWP. According to the result of low-resolution pollen analysis (Figure $7(\mathrm{~g})$ ), the content of tree pollen was high during MWP as well, suggesting forest vegetation around the lake basin. Also the pollen $\mathrm{A} / \mathrm{C}$ ratio indicates that the regional moisture was highest during the MWP, supporting a more optimal climate than that in the Current Warm Period. Compared with conditions in the MWP, the content of tree pollen was lower than $10 \%$ during the LIA, and the pollen $\mathrm{A} / \mathrm{C}$ ratio was also low, which together suggests that the Asian monsoon was weak and the climate was dry during that period.

The high (3-6 years) resolution of the sedimentary magnetic record from Gonghai Lake during the MWP provides us an opportunity to discuss the climate variability on decadal-to-centennial scales. Although the summer monsoon was generally strong in the MWP, secondary oscillations were superimposed on it, of which the most pronounced one lasted from AD 980 to 1850. During that period, the values of $\chi$ and $S_{-300}$ were relatively low, indicating that the degree of pedogenesis and amount of precipitation were also relatively low around the lake basin. It is thus indicated that the MWP was not a period of constantly strong summer monsoons, as there was a centennial-scale interval that features relatively weak summer monsoon.

Figure 7 shows comparisons of the magnetic proxy records with the dry-wet proxy series of North China reconstructed from historical documentation [40] (Figure 7(b)), and the oxygen isotope record of speleothems from Wangxiang Cave [35] (Figure 7(c)) which is also located on the northwestern margin of the modern Asian summer monsoon. On a multi-centennial time scale, the proxy data from these three locations show a consistent climate pattern over the last millennium. In particular, the strong Asian monsoon during the MWP is indicated by high values of $\chi$ and $S_{-300}$ in Gonghai Lake sediments, more flood events in North China, and the light oxygen isotopes recorded in speleothems of Wanxiang Cave, all of which resulted from high monsoon precipitation. Situations were roughly opposite during the LIA. On decadal to centennial time scales, the secondary weakening of the summer monsoon during the 11 th century against the overall strong summer monsoon period during the MWP, which is revealed by the magnetic record of Gonghai Lake sediments, is also evident in the high-resolution series of oxygen isotopes for the speleothems of Wangxiang Cave. In addition, this short-term drought is reflected in the dry-wet proxy reconstruction for North China as well. Therefore, changes in the magnetic parameters of Gonghai Lake sediments sensitively documented the variability of the Asian summer monsoon on the submillennial scale and even shorter time scales. Furthermore, the evolution of the Asian summer monsoon during the last millennium, as indicated by the environmental magnetic pxoxies from Gonghai Lake and oxygen isotopes from Wangxiang Cave speleothems, is supported by the modeling of monsoon rainfall [43] (Figure 7(d)).

The variations in intensity of the summer monsoon (precipitation), which are reconstructed from Gonghai Lake, obviously differ from moisture variability in Central Asia, 
which is dominated by westerlies [29] during the last millennium. This supports the proposal that a "westerlydominated climate model" for arid Central Asia is distinct from precipitation (moisture) evolution in monsoonal Asia over the various time scales during the modern interglacial period $[46,75]$. Note that the generally strong Asian monsoon during the MWP, reconstructed from the observed limits of the monsoon, shows major differences from the monsoon strength reconstructed using cave deposits $[38,76,77]$ and lacustrine sediments [78] from South China, and also differs from the dry-wet index series based on historical documentation in South China [40,41]. To trace the reason for this, consider that the chronological uncertainties are unlikely to have exerted effects upon recorded patterns of climate change on a multi-centennial time scale. Therefore, the above-mentioned differences between precipitation (moisture) records may be the result of different regional responses to the same climate event in monsoon-dominated Eastern China. For example, on the decadal time scale, instrumental data demonstrate that precipitation in North China decreased over the last 50 years, while it increased in Southern China [79]. In fact, based on integrated research, we found that on the multi-centennial time scale during the last millennium, climatic changes in mid-latitude monsoon-dominated China differed from those in westerly-dominated China and moisture variation over monsoonal China has shown clear spatial variability. Such spatial patterns and possible mechanisms will be investigated in the future. Gonghai Lake, located at the margin of the Asian summer monsoon, occupies an ideal position to sensitively record variations in the strength of the monsoon. Changes in the magnetic parameters in its sediments could reflect the evolution of Asian monsoon intensity, which is generally consistent with proxy records derived from surrounding regions and is also supported by models. These advantages, together with relatively high resolution, show the value of paleolimnological records from Gonghai Lake for exploring the past variability of the Asian monsoon.

Note that due to relatively few age control points (four in the past 1000 years), comparisons of decadal-scale climatic events between sites are restricted. Besides the chronological enhancement, future research efforts should include detailed investigations of modern processes and multi-proxy studies. These will help improve explanations of the paleoclimatic significance of magnetic parameters and achieve a complete and profound understanding of paleoenvironment and paleoclimate variations during the last millennium.

\section{Conclusions}

Our investigation of environmental magnetism in Gonghai Lake sediments demonstrates that the main magnetic minerals in the sediments are magnetite and mainly originate from pedogenic processes in the lake drainage basin. The post depositional effects on the magnetic properties of detrital minerals are rather weak. The grain sizes of the main magnetic minerals mostly fall into the SSD category. In general, sediments with relatively high magnetite concentrations are characterized by relatively fine magnetic grain sizes, whereas sediments with relatively low magnetite concentrations are characterized by relatively coarse magnetic grain sizes. This relationship is mainly attributed to environmental conditions in the lake drainage basin, and mainly reflects the degree of pedogenic process and the amount of precipitation around the drainage basin, corresponding to variations in the strength of Asian summer monsoon.

Based on an understanding of paleoclimatic significance of magnetic parameters, the evolution of the Asian summer monsoon over the last 1200 years was reconstructed using $\chi$ and $S_{-300}$ as proxies from Gonghai Lake, Shanxi, North China. The results show that an obviously wet period (AD 910-1220) occurred in this region, suggesting that the summer monsoon was strong and forests were well developed around the lake drainage basin during the MWP. This forms a striking contrast to the generally dry climate that occurred during the MWP in the mid-latitude westerlydominated part of Asia. In addition, against the context of a generally strong summer monsoon, a relatively weak monsoon interval (AD 980-1050) occurred within the MWP in the study area.

The major characteristics of climate change over the last millennium revealed by magnetic proxies in Gonghai Lake sediments are supported by other proxy records derived from monsoon region and models. These paleo-monsoon reconstructions are comparable, even on decadal-to-centennial time scales, demonstrating the ability of magnetic parameters to identify sensitive regional environment changes. The high resolution of these data combined with additional timing constraints mean that records of magnetic proxies from Gonghai Lake are expected to be valuable for the thorough characterization of the evolution of the Asian summer monsoon.

We would like to thank Dr. Cao Xianyong who provided help with fieldwork; Gao Shujun and Dr. Li Qiong who participated in the laboratory analyses; Dr. Hu Shouyun, Wei Haitao, Jia Jia and Lü Bin who made constructive suggestions on this paper. This work was supported by the National Basic Research Program of China (2010CB950202) and the National Natural Science Foundation of China (40971056 and 41001114).

1 Robinson S G. The late Pleistocene palaeoclimatic record of North Atlantic deep-sea sediments revealed by mineral magnetic measurements. Phys Earth Planet Inter, 1986, 42: 22-57

2 Thompson R, Stober J C, Turner G M, et al. Environmental applications of magnetic measurements. Science, 1980, 207: 481-486

3 Thouveny N, Beaulieu J L, Bonifay E, et al. Climate variations in Europe over the past $140 \mathrm{kyr}$ deduced from rock magnetism. Nature, 1994, 371: 503-506

4 Heller F, Liu T S. Magnetism of Chinese loess deposits. Geophys J Int, 1984, 77: 125-141 
5 Kukla G, Hellerf F, Liu X M, et al. Pleistocene climates in China dated by magnetic susceptibility. Geology, 1988, 16: 811-814

6 Thompson R, Oldfield F. Environmental Magnetism. London: Allen Unwin, 1986. 1-127

7 Deng C L, Liu Q S, Pan Y X, et al. Environmental magnetism of Chinese loess-paleosol sequences (in Chinese). Quat Sci, 2007, 27: 193-209

8 Lanci L, Hirt A M, Lowrie W, et al. Mineral-magnetic record of late Quaternary climatic changes in a high Alpine lake. Earth Planet Sci Lett, 1999, 170: 49-59

$9 \mathrm{Hu} \mathrm{S}$, Deng C, Appel E, et al. Environmental magnetic study on lacustrine sediments. Chinese Sci Bull, 2002, 49: 613-616

10 Esper J, Cook E R, Schweingruber F H. Low frequency signals in long tree-ring chronologies for reconstructing past temperature variability. Science, 2002, 295: 2250-2253

11 Juckes M N, Allen M R, Briffa K R, et al. Millennial temperature reconstruction intercomparison and evaluation. Clim Past, 2007, 3: 591-609

12 Mann M E, Zhang Z, Hughes M K, et al. Proxy-based reconstructions of hemispheric and global surface temperature variations over the past two millennia. Proc Natl Acad Sci USA, 2008, 105: 1325213257

13 Mann M E, Zhang Z, Rntherford S, et al. Global signatures and dynamical origins of the Little Ice Age and Medieval climate anomaly. Science, 2009, 326: 1256-1259

14 Moberg A, Sonechkin D M, Holmgren K, et al. Highly variable Northern Hemisphere temperatures reconstructed from low- and high-resolution proxy data. Nature, 2005, 433: 613-617

15 Ge Q S, Zheng J Y, Fang X Q, et al. Winter half-year temperature reconstruction for the middle and lower reaches of the Yellow River and Yangtze River, China, during the past 2000 years. Holocene, 2003, 13: 933-940

16 McIntyre S, McKitrick R. Corrections to the Mann et al. (1998) proxy data based and Northern Hemispheric average temperature series. Energy Environ, 2003, 14: 751-771

17 Soon W H, Legates D R, Baliunas S L. Estimation and representation of long-term ( $>40$ year) trends of Northern-Hemisphere-gridded surface temperature: A note of caution. Geophys Res Lett, 2004, 31: L032091, doi: 10.1029/2003GL019141

18 Jones P D, Mann M E. Climate over past millennia. Rev Geophys, 2004, 42: 1-42

19 Seager R, Graham N, Herweijer C, et al. Blueprints for Medieval hydroclimate. Quat Sci Rev, 2007, 26: 2322-2336

20 Graham N E, Ammann C M, Fleitmann D, et al. Support for global clim reorganization during the "Medieval Climate Anomaly". Clim Dyn, 2010, doi: 10.1007/s00382-010-0914-z

21 Cook E R, Woodhouse C A, Eakin C M, et al. Long-term aridity changes in the Western United States. Science, 2004, 306 : 10151018

22 Proctor C J, Baker A, Barnes W L, et al. A thousand year speleothem proxy record of North Atlantic climate from Scotland. Clim Dyn, 2000, 16: 815-820

23 Charman D J, Blundell A, Chiverrell R C, et al. Compilation of nonannually resolved Holocene proxy climate records: Stacked Holocene peatland palaeo-water table reconstructions from northern Britain. Quat Sci Rev, 2006, 25: 336-350

24 Hodell D A, Curtis J H, Brenner M. Possible role of climate in the collapse of Classic Maya civilization. Nature, 1995, 375: 391-394

25 Chen F H, Huang X Z, Zhang J W, et al. Humid Little Ice Age in arid central Asia documented by Bosten Lake, Xinjiang, China. Sci China Ser D-Earth Sci, 2006, 49: 1280-1290

26 Chen J H, Chen F H, Zhang E L, et al. A 1000-year chironomidbased salinity reconstruction from varved sediments of Sugan Lake, Qaidam Basin, arid Northwest China, and its palaeoclimatic significance. Chinese Sci Bull, 2009, 54: 3749-3759

27 Liu W G, Liu Z H, An Z S, et al. Wet climate during the 'Little Ice Age' in the arid Tarim Basin, northwestern China. Holocene, 2010, doi: $10.1177 / 0959683610378881$

28 Shao X, Xu Y, Yin Z Y, et al. Climatic implications of a 3585-year tree-ring chronology from the northeastern Qinghai-Tibetan Plateau. Quat Sci Rev, 2010, 29: 2111-2122

29 Chen F H, Chen J H, Holmes J, et al. Moisture changes over the last millennium in arid central Asia: A review, synthesis and comparison with monsoon region. Quat Sci Rev, 2010, 29: 1055-1068

30 An Z S. The history and variability of the east Asian paleomonsoon climate. Quat Sci Rev, 2000, 19: 171-187

31 Wang P X, Clemens S, Beaufort L, et al. Evolution variability of the Asian monsoon system: State of the art and outstanding issues. Quat Sci Rev, 2005, 24: 595-629

32 Gong G, Hameed S. The variation of moisture conditions in China during the last 2000 years. Int J Climatol, 1991, 11: 271-283

33 Ren G Y. Pollen evidence for increased summer rainfall in the medieval warm period at Maili, Noertheast China. Geophys Res Lett, 1998, 25: 1931-1934

34 Hou J Z, Tan M, Cheng H, et al. Stable isotope records of plant cover change and monsoon variation in the past 2200 years: Evidence from laminated stalagmites in Beijing, China. Boreas, 2003, 32: 304-313

35 Zhang P Z, Cheng H, Edwards R L, et al. A test of climate, sun, and culture relationships from an 1810-year Chinese cave record. Science, 2008, 322: 940-942

36 He $\mathrm{Y}$, Wang $\mathrm{Y}$, Kong $\mathrm{X}$, et al. High resolution stalagmite $\delta^{18} \mathrm{O}$ records over the past 1000 years from Dongge Cave in Guizhou. Chinese Sci Bull, 2005, 50: 1003-1008

37 Qin J M, Yuan D X, Lin Y S, et al. High resolution stalagmite records of climate change since 800 a A D in Libo, Guizhou (in Chinese). Carsol Sin, 2008, 27: 26-272

38 Yang B, Tan M. Variability of the East Asian summer monsoon and its relationship with regional temperature and moisture change during the last millennium (in Chinese). Quat Sci, 2009, 29: 880-887

39 Zheng J Y, Zhang P Y, Ge Q S, et al. Centennial changes of drought/flood spatial pattern in eastern China for the last 2000 years. Prog Nat Sci, 2001, 11: 280-287

40 Man Z M. The Climate Research During the History Period in China (in Chinese). Jinan: Shandong Education Press, 2009. 316-329

41 Zheng J Y, Wang W C, Ge Q S, et al. Precipitation variability and extreme events in eastern China during the past 1500 years. Terr Atmos Ocean Sci, 2006, 17: 579-592

42 Wang B, Wu Z W, Li J P, et al. How to measure the strength of the East Asian summer monsoon. J Clim, 2008, 21: 4449-4463

43 Liu J, Wang B, Wang H, et al. Forced response of the East Asian summer rainfall over the past millennium: results from a coupled model simulation. Clim Dyn, 2010, doi: 10.1007/s00382-009-0693-6

44 Zhu D G, Meng X G, Shao Z G, et al. Holocene lacustrine deposits in mountain lakes in Ningwu, Shanxi, China and establishment of the Ganhai Formation (in Chinese). Geol Bull Chin, 2006, 25: 13031310

45 Chen F H, Yu Z C, Yang M L, et al. Holocene moisture evolution in arid central Asia and its out-of-phase relationship with Asian monsoon history. Quat Sci Rev, 2008, 27: 351-364

46 Zhu D G, Meng X G, Shao Z G, et al. Paleoclimatic and plaeoenvironmental evolution since holocene in the Ningwu area, Shanxi Province (in Chinese). Acta Geol Sin, 2007, 81: 316-323

47 Dearing J A. Magnetic susceptibility. In: Walden J, Oldfield F, Smith J, eds. Environmental Magnetism: A Practical Guide No. 6. London: Quaternary Research Association, 1999. 35-62

48 Moore P D, Webb J A, Collinson M E. Pollen Analysis. Oxford: Blackwell Science, 1991. 39-62

49 Bronk R C. Bayesian analysis of radiocarbon dates. Radiocarbon, 2009, 51: 337-360

50 Reimer P J, Baillie M G L, Bard E, et al. IntCal04 terrestrial radiocarbon age calibration, 0-26 cal kyr BP. Radiocarbon, 2004, 46: $1029-1058$

51 Liu Q S, Deng C L, Yu Y J, et al. Temperature dependence of magnetic susceptibility in an argon environment: Implications for pedogenesis of 
Chinese loess/palaeosols. Geophys J Int, 2005, 161: 102-112

52 Sun Z M, Hu S Y, Ma X H. A rock-magnetic study of recent lake sediments and its palaeoenvironmental implication (in Chinese). Acta Geophys Sin, 1996, 39: 178-187

53 Peters C, Dekkers M J. Selected room temperature magnetic parameters as a function of mineralogy, concent ration and grain size. Phys Chem Earth, 2003, 28: 659-667

54 Meng Q Y, Li A C, Li T G, et al. Rock magnetic properties of the West Philippine Sea sedimens and its Paleoenvironmental Significances (in Chinese). Prog Nat Sci, 2009, 19: 868-876

55 Day R, Fuller M D, Sehmidt V A. Hysteresis properties of titanomagnetite: Grain size and composition dependence. Phys Earth Planet In, 1997, 13: 260-267

56 Dunlop D J. Theory and appfication of the Day plot $\left(M_{\mathrm{rs}} / M_{\mathrm{S}}\right.$ versus $\left.H_{\mathrm{cr}} / H_{\mathrm{c}}\right), 1$, Theoretical curves and tests using titanomagnetite data. $\mathrm{J}$ Geophys Res, 2002, 107: 2056, doi: 10.1029/2001JB00487

57 Dunlop D J. Theory and application of the Day plot $\left(M_{\mathrm{rs}} / M_{\mathrm{s}}\right.$ versus $\left.H_{\mathrm{cr}} / H_{\mathrm{c}}\right), 2$, Application to data for rocks, sediments and soils. J Geophys Res, 2002, 107: 2057, doi: 10.1029/2001JB00487

58 Ao H, Deng C L. Review in the identification of magnetic minerals (in Chinese). Prog Geophys, 2007, 22: 432-442

59 Dearing J A, Bird P M, Dann R J L. Secondary ferrimagnetic minerals in Welsh soils: A comparison of mineral magnetic detection methods and implications for mineral formation. Geophys J Int, 1997, 130: 727-736

60 Xia D S, Yang L P, Ma J Y, et al. Magnetic property of Lanzhou dustfall and its implication in urban pollution. Sci China Ser D-Earth Sci, 2007, 50: 1724-1732

61 Bloemendal J, King J W, Hall F R, et al. Rock magnetism of Late Neogene and Pleistocene deep-sea sediments: Relationship to sediment source, diagenetic process and sediment lithology. J Geophys Res, 1992, 97: 4361-4375

62 Wang X S, Lovlie R, Pu S, et al. Magnetic signature of environmental change reflected by Pleistocene lacustrine sediments from the $\mathrm{Ni}$ hewan Basin, North China. Palaeogeogr Palaeoclimatol Palaeoecol, 2008, 260: 452-462

63 Banerjee S K, King J, Marvin A J. Rapid method for magnetic granulometry with applications to environmental studies. Geophys Res Lett, 1981, 8: 333-336

64 Heider F, Zitzelsoberger A, Fabian K. Magnetic susceptibility and remanent coercive force in grown magnetite crystals from $0.1 \mu \mathrm{m}$ to 6 mm. Phys Earth Planet Inter, 1996, 93: 239-256

65 Moskovitz B M, Frankel R B, Bazylinski D A. Rock magnetic criteria for the detection of biogenic magnetite. Earth Planet Sci Lett,
1993, 120: 283-300

66 Oldfield F. Toward the discrimination of fine-grained ferrimagnets by magnetic measurements in lake and near-shore marine sediments. J Geophys Res, 1994, 99: 9045-9050

67 Oldfield F, Dearing J A, Thompson R, et al. Some magnetic properties of lake sediments and their possible links with erosion rates. Pol Arch Hydrobiol, 1978, 25: 321-331

68 Zhou L P, Oldfield F, Wintle A G, et al. Partly pedogenic origin of magnetic variations in Chinese Loess. Nature, 1990, 346: 737-739

69 Lu H Y, Han J M, Wu N Q, et al. Implication of magnetic susceptibility from modern soils in China (in Chinese). Sci China Ser B, 1994, 24: $1290-1297$

70 Chen F H, Bloemendal J, Wang J M, et al. High-resolution multi-proxy climate records from Chinese Loess: Evidence for rapid climatic changes over the last 75 kyr. Paleogeogr Paleoclimatol Palaeoecol, 1997, 130: 323-335

71 Sun X J, Du N Q, Weng C Y, et al. Plaeovegetation and palaeoenvironment of Manasi Lake Xinjiang, N. W. China during the last 14000 years (in Chinese). Quat Sci, 1994, 3: 239-248

72 Liu H Y, Wang Y, Tian Y H, et al. Climatic and anthropogenic control of surface pollen assemblages in East Asian steppes. Rev Palaeobot Palynol, 2006, 138: 281-289

73 Zheng Z, Huang K Y, Xu Q H, et al. Comparison of climatic threshold of geographical distribution between dominant plants and surface pollen in China. Sci China Ser D-Earth Sci, 2008, 51: 1107-1120

74 Zhao Y, Yu Z C, Chen F H, et al. Sensitive response of desert vegetation to moisture change based on a near-annual resolution pollen record from Gahai Lake in the Qaidam Basin, northwest China. Glob Planet Change, 2008, 62: 107-114

75 Chen F H, Chen J H, Huang W. A discussion on the westerly-dominated climate model in mid-latitude Asia during the modern interglacial period (in Chinese). Earth Sci Front, 2009, 16: 23-32

76 Wang Y J, Cheng H, Edwards R L, et al. The Holocene Asia monsoon: Links to solar changes and North Atlantic climate. Science, 2005, 308: 854-857

$77 \mathrm{Li} \mathrm{H} \mathrm{C}$, Lee $\mathrm{Z} \mathrm{H}$, Wang $\mathrm{N} \mathrm{J}$, et al. The $\delta^{18} \mathrm{O}$ and $\delta^{13} \mathrm{C}$ records in an aragonite stalagmite from Furong Cave, Chongqing, China: A-2000year record of monsoonal climate. J Asian Earth Sci, 2010, doi: 10.1016/j.jseaes.2010.06.011

78 Chu G, Liu J, Sun Q, et al. The 'Mediaeval Warm Period' drought recorded in Lake Huguangyan, tropical South China. Holocene, 2002, 12: $511-516$

79 Ma Z G, Fu C B. Some evidences of drying trend over North China from 1951 to 2004. Chinese Sci Bull, 2006, 51: 2913-2925

Open Access This article is distributed under the terms of the Creative Commons Attribution License which permits any use, distribution, and reproduction in any medium, provided the original author(s) and source are credited. 